\title{
Prevalence and Factors Associated with the Use of Illicit Substances among Male University Students in Kuwait
}

\author{
Hisham Z. Bajwa Ahmed S.A. Al-Turki Ahmed M.K. Dawas \\ Mohammad Q. Behbehani Abdulaziz M.A. Al-Mutairi \\ Shaymaa Al-Mahmoud Mumtaz Shukkur Lukman Thalib
}

Department of Community Medicine and Behavioural Sciences, Faculty of Medicine, Kuwait University, Kuwait, Kuwait

\section{Key Words}

Prevalence · Illicit stimulants · Substance abuse · College students

\begin{abstract}
Objectives: To estimate the prevalence of illicit use of substances and identify the factors associated with illicit drug use among male students in the state-run Kuwait University and private universities in Kuwait. Subjects and Methods: The study was a cross-sectional survey with a sample of 1,587 male students from both private universities $(n=869)$ and the public $(n=718)$ Kuwait University in Kuwait. A selfadministered questionnaire was used to collect data. Overall lifetime prevalence of substance use was computed with $95 \%$ confidence interval. Logistic regression was used to identify the factors influencing substance use, which was adjusted for potential confounders. Results: The total lifetime prevalence of illicit drug use was $14.4 \%$ and the most frequently used illicit substance was marijuana (11\%). The substance use in general varied significantly $(p \leq 0.001)$ between private (18\%) and public (10\%) universities. Multivariate logistic regression model revealed that drug use was positively associated with age, poor academic performance, high family income, being an only child, divorced parents, and
\end{abstract}

graduation from a private high school. Conclusion: Drug use among male university students in Kuwait was high and requires attention and appropriate intervention. The factors identified with drug use in this study could be utilized to develop appropriate public health policies and preventive measures that may improve the health status of the student population.

Copyright $\odot 2013$ S. Karger AG, Basel

\section{Introduction}

The extent of worldwide use of psychoactive substances has been estimated as follows: alcohol users -0.2 billion; smokers - 1.3 billion; illicit drug users -0.85 million [1]. The World Health Organization (WHO) has estimated that tobacco, alcohol and illicit drugs together contributed to $12.4 \%$ of all deaths worldwide [2]. The misuse of drugs can ultimately lead to social and financial problems, legal issues, morbidity and mortality, homicides and suicides, violence, injuries, motor vehicle accidents, psychological addiction or physical dependence [2]. Experimentation with drugs can begin as early as high school and sometimes even earlier $[3,4]$, and such experimentation may be an important indicator of future persistent drug use.

Dr. Lukman Thalib

Department of Community Medicine and Behavioural Sciences Faculty of Medicine, Kuwait University

PO Box 24923, Kuwait (Kuwait)

E-Mail lthalib@ hsc.edu.kw 
Substance use among college and university students remains an important area of research due to the implications of early dependence on the future of young people. They are a particularly high-risk group for substance-related problems; alcohol and drug usage in this population is growing and has become a major concern in many countries $[5,6]$, particularly among male students $[7,8]$.

Various studies in different countries indicate high rates of substance use among high school and college students [9-11]. Compared to the Western world, the topic of drug use has only been superficially studied in the Middle East and data for Kuwait on the prevalence of drug use is non-existent. Previous studies have shown that substance abuse by parents, siblings or peers, as well as family problems, poor school performance, mood or anxiety disorders, use of tobacco and/or alcohol, history of physical or sexual abuse, and other behavioural problems may be related to the risk of substance abuse in young adults. No systematic study has been attempted to validate these factors in this region. Given the current paucity of data regarding drug use in Kuwait, this study aimed to determine the prevalence of substance abuse and its contributing factors among male university students in Kuwait.

\section{Subjects and Methods}

The study was a cross-sectional survey with a sample of 1,587 students from both private universities $(n=869)$ and Kuwait University (KU, $n=718$ ). KU, which is comprised of 11 different faculties, is the major and only public university, whereas there are a few private universities which are smaller in strength and hence were considered as single entities for the study.

Students were selected from 3 randomly selected faculties of KU, i.e. College of Social Sciences $(n=193)$, College of Business Administration $(n=168)$ and College of Sciences $(n=357)$, and from 3 of the most populous private universities, i.e. American University of Kuwait ( $\mathrm{n}=155)$, Australian College of Kuwait $(n=391)$ and Gulf University of Science and Technology $(n=323)$.

This study was approved by the Joint Committee for the Protection of Human Subjects in Research, Health Sciences Centre, $\mathrm{KU}$. Required permission was also received from the administration departments of the other universities selected for the study. The timetables of all the classes for the selected faculties were obtained and data collection was done until the target sample size was reached. A priori sample size determination was done.

The questionnaire was adapted from WHO guidelines titled 'A Methodology for Student Drug Use Surveys' [12]. However, questions regarding hypnotics, anxiolytics, phencyclidine and hallucinogens were deleted as they were not relevant to the objectives and these drugs. The modified questionnaire inquired about the use of alcohol, amphetamine, cannabis (hashish and/or marijuana), cocaine and heroin. The questionnaire was translated into Arabic by language experts and a pilot study was carried out

Illicit Substance Use among University

Students in Kuwait on 20 students from the Health Sciences Centre of KU to check the reliability of the questionnaire. The final questionnaire was prepared with no major modifications.

After explaining the objectives of the study and informing the students that participation was voluntary and anonymous, written consent was obtained from each participant and the students were asked to choose the questionnaire in either Arabic or English. After completing the questionnaire, students were asked to place it in the boxes provided by the research team in each class in the selected university to ensure additional confidentiality. All questionnaires were completed inside the classroom either at the beginning or end of the class and the process took about 5-10 minutes. The students were classified into those who had never taken any illicit drugs (i.e. marijuana, cocaine, heroin and stimulants) and those who had taken at least 1 of them.

The analysis was done on SPSS (Statistical Package for Social Sciences, version 17.0). A value of $\mathrm{p}<0.05$ was taken as the significance level. The prevalence along with the corresponding $95 \%$ confidence interval ( $95 \%$ CI) was computed for overall substance use, as well as for specific drugs. Using univariate logistic regression, any of the sociodemographic factors that were significantly associated with illicit drug use were identified. Stepwise multiple logistic regression models were used to identify those factors that were independently and significantly associated with illicit drug use, along with the mutually adjusted odds ratio (OR) for illicit drug use. Furthermore, the analysis was repeated for all the substances (tobacco, alcohol, sedatives and inhalants) in the same way, using univariate and multivariate logistic regression models. In addition, $\chi^{2}$ analysis was used to establish the relationship between the initiation of smoking and use of illicit drugs and alcohol. A similar method was used to determine the number of people who had taken multiple substances and drugs.

\section{Results}

Of the 1,587 questionnaires, 1,473 were completed, giving a response rate of $92.8 \%$. The overall mean age of the students was $20.3 \pm 2.9$ years (private universities = $20.8 \pm 3.0$ vs. $\mathrm{KU}=19.7 \pm 2.6$ ). The overall lifetime prevalence for the use of illicit drugs in the sample at large was $14.4 \%$; private university students consumed significantly ( $\mathrm{p} \leq 0.001$ ) more than KU students (table 1). With regard to specific drugs, cannabis (marijuana/ hashish) was the most commonly used illicit drug, with 174 (11.0\%; 95\% CI $=9.5-12.7)$ of all students having taken it at least once. There was also significantly ( $\mathrm{s}$ 0.001 ) more use of cannabis among private university students than the students of KU. The crude prevalence values for the lifetime use of stimulants, cocaine and heroin were $7.1 \%(5.9-8.6), 2.2 \%(1.6-3.1)$ and $1.3 \%(0.8-$ $2.0)$, respectively, and the lifetime use for each of these substances was higher in private institutions than KU. The proportion of students who had used cannabis re- 
Table 1. Prevalence of lifetime, last 12 months and last 30 days illicit drug use in public and private male university students in Kuwait $(\mathrm{n}=1,583)$

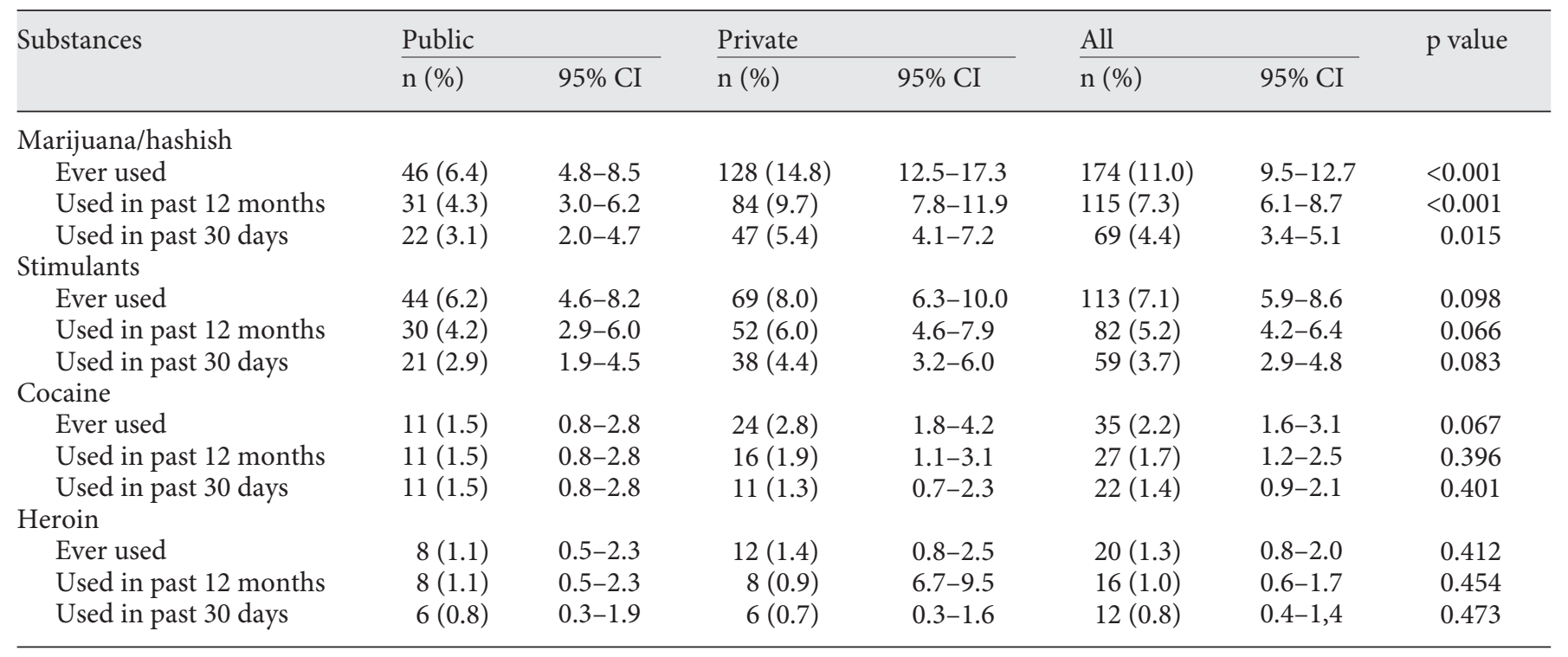

cently was less than half of the lifetime prevalence of the drug in the respective universities, with $5.4 \%$ (4.1-7.2) in private universities and $3.1 \%(2.0-4.7)$ in $\mathrm{KU}$.

The age of initiation varied depending on the substances; for non-illicit substances the distribution was mainly in the younger age group of 14-16 years, while for alcohol and illicit substances the age of first use tended to be 17-18 years. This relationship was similar across private universities and KU. In the age group of 14-16 years, 398 (42.0\%) initiated with smoking, while the 17- to 18-year age group marked a peak for the initiation of 3 substances: stimulants 46 (41.8\%), sedatives 128 (40.7\%) and alcohol 115 (43.1\%). The most frequently associated age group with the first use of inhalants was 13 years or less. Among 171 students who initiated with cannabis, $132(77.2 \%)$ were found to have begun using this substance at the age of 17 or above, whereas among the 37 students who initiated with cocaine, 16 (43.2\%) began taking the substance at 19 years or more.

Tobacco smoking was found to be a gateway to more dangerous drugs like cannabis, stimulants and cocaine. A similar relationship was also seen with alcohol, as 168 $(61.7 \%)$ of those who had at least tried alcohol were smokers prior to doing so $(\mathrm{p}<0.001)$.

The factors associated with illicit drug use, the type of high school, level of academic performance, combined family income, marital status of parents, number of siblings, and age are presented in table 2 . The age of the students was significantly associated with the use of illicit sub- stances even after adjusting for other significant predictors $(p=0.017)$. For every yearly increase in age, the odds of illicit substance use increased by $10 \%$. The most important factor in the context of drug use was the perceived level of academic achievement. As academic performance, or the perception thereof, dropped, the odds of drug use became higher. Family income was found to be positively associated with illicit drug use. Students from the highest income category had an adjusted OR of $1.8(1.1-2.8)$ for the use of illicit drugs compared to the lowest income categories. The marital status of the parents was also a prominent factor in drug use, as students with divorced parents had higher odds of taking substances. There was a negative association between the number of siblings and illicit drug use. The adjusted OR was $3.6(1.6-8.3)$ with a p value of 0.002 for those with no siblings compared to those who had more than 5 siblings. The majority of drug users (127, $55.9 \%)$ first obtained the drug from friends. With regard to the underlying reason for their first use of an illicit substance, $81(35.7 \%)$ said it was for enjoyment, while 79 $(34.8 \%)$ cited curiosity as the driving motivation.

\section{Discussion}

A significantly higher percentage of private university students had used illicit substances compared to their peers in KU. However, by adjusting for various 
Table 2. Univariate and multivariate analyses of risk factors for illicit drug use

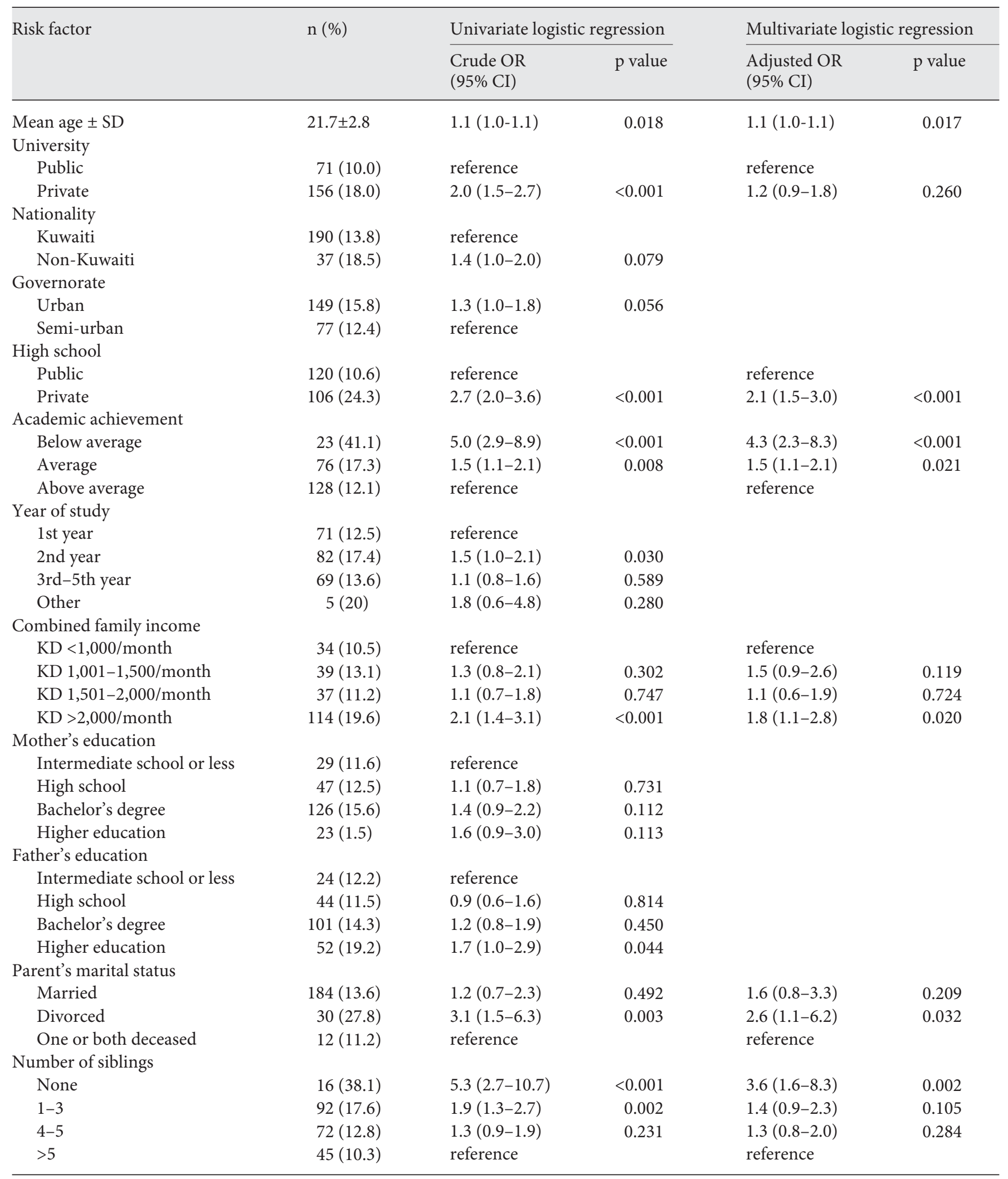


confounding factors, it became evident that the difference in prevalence was not due to intrinsic attributes of the universities themselves but rather a result of the differences in the sociodemographic and socioeconomic characteristics of the two groups of students.

The overall lifetime prevalence of illicit drug use in male university students was $14.4 \%$, which was less than a third of the lifetime prevalence in the same population in the USA, where it was $50.7 \%$ [13]. The relative scarcity in the availability of drugs as well as the social norms and religious values in Kuwait probably account for the difference in prevalence of drug use in Kuwait. Data on the prevalence of substance use among countries in the Middle East are scarce. However, our findings suggest that, relative to at least two other countries in the Middle East, the prevalence of substance use in Kuwait was higher: $10.1 \%$ in a Turkish study [14] and $12.6 \%$ in an Iranian study [15].

By far the most commonly used illicit substance was cannabis $(11 \%)$. This may be explained by the so-called 'gateway effect' in which marijuana is usually the first step into the world of illicit drugs, as evidenced by the study of Lessem et al. [16], in which marijuana users were twice as likely to use illicit drugs as non-users. However, there is an alternative theory which explains that very few members of the general population become persistent daily hard drug-using criminal offenders and an increasing percentage of daily hard drug-using criminal offenders did not follow the gateway sequence of substance use progression $[17,18]$. The use of gateway drugs by youth is not the central cause of hard drug use and its associated problems. The large gap in the prevalence of cannabis use and that of other illicit substances in Kuwait is possibly explained by the relative cost and scarce availability of other illicit drugs such as cocaine and heroin.

Graduation from a private high school was a significant predictor of illicit drug use as opposed to public high schools; influences at a younger age might have greater effect on an individual and thus might be more likely to influence behaviour.

This study also uncovered a strong relationship between low academic performance and substance use. This is in conformity with another study which reported that low grades were more prevalent among frequent smokers compared to all other students, and among regular marijuana users compared to non-users [19]. One possible explanation is offered by the psychogenic theory, which states that students initiate or accelerate substance use behaviours as a means to cope with their anxiety over academic failure [20]. Other explanations, which may work together with the above, are that substance use reduces academic motivation [20] and could impair cognitive ability [7].

In contrast to a study in the USA [21], our study found that students who come from families who earn higher incomes were more likely to use illicit drugs. The marital status of parents can also be considered as a significant predictor of drug use. Similar findings have also been reported elsewhere [22]. Perhaps this is because children and adolescents, due to the traumatic experience, are more likely to fall prey to drug-promoting influences or engage in drug-seeking behaviour.

Age was found to be a significant risk factor for the use of illicit drugs. Arria et al. [3] reported similar findings. Determining the age of initiation for various drugs helps to identify high-risk groups, which subsequently guides the design and implementation of preventive measures. Gledhill-Hoyt et al. [4], for instance, investigated the age of initiation for several substances including tobacco, alcohol and marijuana and established that the initiation of cigarette smoking usually preceded the other substances, effectively mediating as a gateway drug. The peak age for initiation in the afore-mentioned study was 13-15 years for cigarettes and 16-17 years for marijuana and alcohol. These findings were analogous to ours as we found that the initiation of smoking peaks between 14 and 16 years of age, whereas alcohol and marijuana peak at 17-18 years of age.

A large intercontinental study that included the Netherlands, USA, Ontario (Canada), Sao Paulo (Brazil), Munich (Germany), Fresno (USA) and Mexico City (Mexico) established that despite differential prevalence of substance use, patterns relating to age of initiation were uniform across all regions [8]. The analyses showed that the peak age of first use for cocaine, stimulants and alcohol was 18 years in all the above places, which is consistent with our study.

The study was limited to male students. Estimates obtained for drug use may not be very precise due to potential under-reporting and, consequently, the true differences between the institutions for such drugs may not have been correctly estimated in the study.

\section{Conclusion}

Drug use among male university students in Kuwait was high. The factors identified with drug use in this study could be utilized to develop appropriate public health policies and preventive measures that may improve the health status of the population. 


\section{References}

1 WHO: The Global Burden. Management of Substance Abuse. WHO, 2012.

-2 Burke PJ, O’Sullivan J, Vaughan BL: Adolescent substance use: brief interventions by emergency care providers. Pediatr Emerg Care 2005;21:770-776.

- 3 Arria AM, Caldeira KM, O'Grady KE, et al: Drug exposure opportunities and use patterns among college students: results of a longitudinal prospective cohort study. Subst Abus 2008;29:19-38.

4 Gledhill-Hoyt J, Lee H, Strote J, et al: Increased use of marijuana and other illicit drugs at US colleges in the 1990s: results of three national surveys. Addiction 2000;95: 1655-1667.

5 Read JP, Wood MD, Davidoff OJ, et al: Making the transition from high school to college: the role of alcohol-related social influence factors in students' drinking. Subst Abus 2002; 23:53-65.

6 Simons JS, Gaher RM, Correia CJ, et al: An affective-motivational model of marijuana and alcohol problems among college students. Psychol Addict Behav 2005; 19:326334.

7 Johnson RJ, Kaplan HB: Stability of psychological symptoms: drug use consequences and intervening processes. J Health Soc Behav 1990;31:277-291.
8 Vega WA, Aguilar-Gaxiola S, Andrade L, et al: Prevalence and age of onset for drug use in seven international sites: results from the international consortium of psychiatric epidemiology. Drug Alcohol Depend 2002; 68:285-297.

-9 Ayvasik HB, Sümer HC: Individual differences as predictors of illicit drug use among Turkish college students. J Psychol 2010;144: 489-505.

10 Diamond GM, Farhat A, Al-Amor M, et al: Drug and alcohol use among the Bedouin of the Negev: prevalence and psychosocial correlates. Addict Behav 2008;33:143-151.

11 Momtazi S, Rawson R: Substance abuse among Iranian high school students. Curr Opin Psychiatry 2010;23:221-226.

12 WHO: A Methodology for Student Drug Use Surveys. http://whqlibdoc.who.int/offset/WHO_OFFSET_50.pdf.

13 Johnston LD, O'Malley PM, Bachman JG Schulenberg JE: Monitoring the Future National Survey Results on Drug Use, 19752008. Volume II. College Students and Adults Aged 19-50 (NIH publication No 09-7403). Bethesda, National Institute on Drug Abuse, 2009, pp 75-87.

14 Ilhan IO, Yildirim F, Demirbas H, et al: Prevalence and sociodemographic correlates of substance use in a university student sample in Turkey. Int J Public Health 2009;54:40-44.

15 Ahmadi J, Yazdanfar F: Current substance abuse among Iranian university students. Addict Disord Ther Treat 2002;1:61-64.
16 Lessem JM, Hopfer CJ, Haberstick BC, et al: Relationship between adolescent marijuana use and young adult illicit drug use. Behav Genet 2006;36:498-506.

17 Golub A, Johnson BD: The misuse of the 'gateway theory' in US policy on drug abuse control: a secondary analysis of the muddled deduction. Int J Drug Policy 2002;13:5-19.

18 Van Leeuwen PA, Verhulst CF, Reijneveld AS, et al: Can the gateway hypothesis, the common liability model and/or the route of administration model predict initiation of cannabis use during adolescence? A survival analysis - the TRAILS Study. J Adolesc Health 2011;48:73-78.

19 Cox RG, Zhang L, Johnson WD, et al: Academic performance and substance use: findings from a state survey of public high school students. J Sch Health 2007;77:109-115.

20 Beman DS: Risk factors leading to adolescent substance abuse. Adolescence 1995;30:201208.

21 SAMHSA - Substance Abuse and Mental Health Services Administration: National Survey on Drug Use and Health, 2009. http:// www.samhsa.gov/.

22 Neher LS, Short JL: Risk and protective factors for children's substance use and antisocial behavior following parental divorce. Am J Orthopsychiatry 1998;68:154-161. 